\title{
Ocean -The Biomedical Frontier
}

\author{
Kamakhya Pada Biswas* \\ University of Animal and Fishery Sciences, India \\ *Corresponding author: Kamakhya Pada Biswas, 48, Boral Main Road, P.0 Garia, Kolkata, West Bengal, India
}

Submission: 盎 March 05, 2018; Published: 每 April 18, 2018

\section{Editorial}

In 1928, with the discovery of penicillin in bread mould by Sir Alexander Fleming, a revolution sparked in drug development. Researchers started diligently shifting through soil and plants in search of new weapons to fight disease. In fact, many of today's pharmaceuticals came from terrestrial sources. Morphine came from opium poppy. Aspirin was found in the bark of a willow tree. Digitalis, a heart medication came from the foxglove plant. Bacteria, fungi and other soil microbes also gave to an army of antibiotics and antifungals used to treat everything from strep throat to pneumonia. With the rise in the number of infectious agents that are resistant to known antibiotics, the scientists have begun to look to the tiniest organisms in the sea as new source of drugs. For more than eighty five years, people have spent huge amounts of money scouring through dirt to find micro-organisms to produce drugs, and there are more than a hundred such drugs in the market right now. It is clear, however, that we need to find new resources to supplement those upon which we have traditionally relied. While searching continues on finding novel compounds in large marine organisms, such as, soft corals, tunicates etc, a new laboratory was established in 1991 that focuses exclusively on microbial organisms found in the oceans. One of the greatest advantages of working with marine microbes, rather than larger marine organisms is that microbes can be cultured and grown in the laboratory rather than having to be continually collected from the sea.

Researchers extract compounds from the flasks filled with scary-looking microbes and pour them into tall column shaped beakers containing organic solvents in order to separate them into their various components. These purified chemicals are then put through a variety of tests, including a bioassay to determine if they are effective in killing human cancer cells. Those showing promise are identified using nuclear magnetic resonance spectrometry, a method that allows to identify each atom in a molecule's structures. Despite more than twenty five years of diving around the world oceans in search of unique marine creatures, William Fenical was baffled when he came across a strange yellow coral growing on an under water boulder in the Indian Ocean. Soft corals, just don't look like that, they looked like fingers sticking out all over the rock. The coral named Eleutherobia turned out to be a rare species of soft coral that shows great promise as a potential drug to fight breast and ovarian cancer. Fenical discovered Eleutherobia in 1993, while diving off the northwest coast (Bennett's Shoal) of Australia.

Patented in 1996 and licensed to Bristol-Myers Squibb, a chemical called eleutherobin, extracted from the coral Eleutherobia appear to function similarly to taxol in preventing cancer cells from dividing. Heralded as a breakthrough treatment for breast and ovarian cancer, taxol is found in the bark of the Pacific yew tree. Because extracting the product resulted in the death of the slowgrowing tree, the farm began producing semi-synthetic version of the drug from three's needles. While it is a potent weapon against cancer, taxol is difficult to administer and has serious side effects including immune system suppression, nausea and hair loss. While studying this coral in the laboratory, after extracting the chemical, when it was tested in a standard bioassay for its activity against human colon cancer cells, the researcher was stunned to see that the stuff was so extraordinarily potent, that it was dangerous to handle. Diluting it to a million-fold, it still killed cells very powerfully. Further tests showed that eleutherobin mimics taxol's very unusual method of blocking cell division. Like taxol, it binds to cellular structures called microtubules, which are part of the mitotic spindle and play a key role in cell division. Once eleutherobin has attached to the microtubules, they become extremely rigid and prevent cancer cells from dividing. Coral skeletons belonging to the group, Scleractinian are used as building material and in bone grafts, as the structure of the coral skeleton is similar to that of human bone. The octo-corals in particular, produce a range of bioactive compounds; some of them have been used in molecular, biological and pharmaceutical applications, including anti-cancer and anti-inflammatory agents.

Enzymes from bacteria inhabiting waters near the boiling point in hydrothermal vents at sea beds are being tested for their ability to consume toxic wastes and oil spills. An enzyme Tag-DNA polymerase extracted from thermophilic bacteria. Thermophilus aquaticus inhabiting hot springs in the seas is extensively being used in molecular diagnostics. So far more than 2000 species of marine life have been examined of which $40 \%$ of the species with bioactive chemicals come from corals and their relatives. With so much to choose from, how do scientists know which marine organisms are to be collected? The key is to look for organisms that appear to defend themselves chemically, rather than rely on the protection of 
such things, as shells and spines, or the mobility to run away and hide. There is an inverse correlation between physical protection and chemical protection. While going out on the reef, if something looks like a large chunk of food, soft-bodied, poorly protected and easy to grab, and nothing is eating it, then it can be assumed to have chemical protection.

Scientist's works on marine based pharmaceuticals stemmed from their earlier interests in the roles chemical play in the ecology of the ocean. They wanted to learn more about how marine organisms use chemical compounds to signal each other, to ward off predators, and to mate. At the beginning, it was an academic interest in how the ocean works, especially in highly competitive tropical environments, where everything is trying to eat everything els. The ocean can contribute enormously to the cure and understanding of human disease. The goal is to take advantage of these vast resources. Here is the vast resource out there in the ocean that has been completely overlooked despite the fact that the oceans form the majority of earth's surface.
Creative Commons Attribution 4.0

International License

For possible submissions Click Here

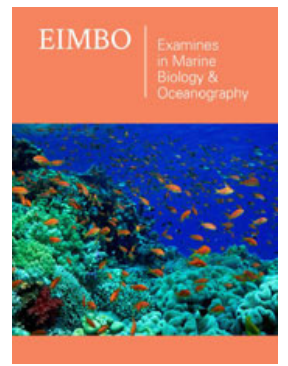

Examines in Marine Biology \& Oceanography

\section{Benefits of Publishing with us}

- High-level peer review and editorial services

- Freely accessible online immediately upon publication

- Authors retain the copyright to their work

- Licensing it under a Creative Commons license

- Visibility through different online platforms 